\title{
Gestão ambiental em escolas públicas do município de Erechim
}

\author{
Analysis of water management resources in the municipality of Erechim \\ Franciele Staczak \\ Gestão Ambiental em Escolas Públicas do município de Erechim, - RS - Brasil
}

\begin{abstract}
Resumo
Este trabalho foi desenvolvido com objetivo de avaliar a Gestão Ambiental (GA) implantada nas escolas públicas do município de Erechim - RS, procurando estabelecer a relação entre Educação Ambiental (EA) e Gestão Ambiental, bem como demonstrar sua importância para o enfrentamento dos desafios socioambientais. A técnica utilizada para a coleta de dados foi entrevista semi-estruturada, tendo como base um questionário de 26 questões, direcionado aos principais gestores das escolas públicas do município de Erechim. Como resultado, a pesquisa revelou que parte significativa dos entrevistados não apresenta boa percepção sobre o que é gestão ambiental e sua importância no ambiente escolar, além de desconhecer a fundamental relação que existe entre EA e GA. Quanto à questão do gerenciamento dos aspectos ambientais, verificou-se que a maioria das escolas atua apenas com ênfase na separação do lixo, e inexiste o gerenciamento dos demais aspectos, como uso racional da água, cuidado com a arborização, canteiros e monitoramento da disposição correta dos resíduos. Nesse sentido, infere-se que as direções das escolas não estão preparadas para trabalhar com a GA e EA, de maneira que consigam relacionar uma com a outra, o que não condiz com as boas praticas sustentáveis que o ambiente escolar deve propiciar. A análise dos dados também propiciou que se fizessem algumas propostas e sugestões às escolas, como por exemplo, um curso direcionado aos administradores das escolas sobre GA e EA, e um PGAE (Plano de Gestão Ambiental Escolar), que seja contínuo, permanente e que venha a contribuir de forma significativa para o processo de conservação ambiental.
\end{abstract}

Palavras-chave: Gestão Ambiental. Educação Ambiental. Legislação Ambiental.

\begin{abstract}
This work was developed with the objective to evaluate the Environmental Management (EM) implemented in public schools in the municipality of Erechim - RS, trying to establish a relationship between Environmental Education (EE) and Environmental Management (EM), as well as to demonstrate their importance to face the socioenvironmental challenges. The technique used for the data collection was a semi-structured interview, using as a 26-question questionnaire as a basis, aimed at the administrators of public schools in the municipality of Erechim. As a result, the research revealed that a significant part of the interviewed do not possess a good perception about what environmental management is and its importance in the school environment, in addition to being unaware the fundamental relationship that there is between EE and EM. In issues regarding the management of environmental aspects, it was verified that most schools act only with emphasis on garbage separation and there is not the management of the remaining aspects such as the rational usage of water, care with afforestation, beds of plants and monitoring the correct disposal of waste. Thus, it is inferred that the administration of schools are not prepared to work with EE and EM in a way that they can relate one with the other, which is not consistent with good sustainable practices that the school environment should provide. The analysis of the data also favored that some proposals and suggestions were made to schools, for example, a course aimed at school administrators about EE and EM, and a School Environmental Management Plan (SEMP), which should be continuous, permanent and that will contribute significantly to the process of environmental conservation.
\end{abstract}

Keywords: Environmental Management. Environmental Education. Environmental Legislation 


\section{INTRODUÇÃO}

De acordo com Vilela Jr. e Demajorovic (2006), as questões ambientais estão presentes em todos os setores da sociedade, por isso se faz necessário compreender como deve ser a gestão ambiental. O sistema de gestão ambiental pode ser definido como parte de uma organização utilizada para desenvolver e implementar sua política ambiental e para gerenciar seus aspectos ambientais. A sua relevância para a sociedade, uma vez que a mesma tem enfrentado diversos desequilíbrios ambientais, é que esta ferramenta se manifeste por meio de normas, as quais se refletem no arcabouço legal e jurídico, com atuação no planejamento, operação e controle ambiental voltado para o controle de poluição e minimização dos impactos ambientais.

A Política Nacional de Educação Ambiental - PNEA (LF 9.795/1999) ressalta que a Educação Ambiental é um componente essencial e permanente à educação nacional, cabendo ao poder público promover o engajamento da sociedade para a melhoria da qualidade ambiental. Cabe também às instituições públicas escolares promover a educação ambiental de maneira integrada aos programas educacionais que desenvolvem, proporcionando desta maneira a formação individual e coletiva de cidadãos que consigam identificar, prevenir e solucionar problemas ambientais. Desta forma pode se fomentar o desenvolvimento de um país ambientalmente equilibrado, fundamentado nos princípios da sustentabilidade.

Conforme a Agenda 21 (Rio 92, p.339), "o ensino tem fundamental importância na promoção do desenvolvimento sustentável e para aumentar a capacidade do povo para abordar questões de meio ambiente e desenvolvimento". A educação se apresenta como um processo de grande influência por permitir a formação sociocultural do sujeito, possibilitando trabalhar os valores éticos, morais e ambientais do indivíduo. E como instituição social a escola pode ser propulsora de convivência sustentável, desde que as práticas pedagógicas estejam de acordo com os princípios da Educação Ambiental. Esse processo pode ser concretizado e dinamizado com a elaboração de um Plano de Gestão Ambiental Escolar (PGAE).

O propósito deste trabalho foi relatar e analisar a gestão ambiental e sua relação com a educação ambiental nas escolas públicas do município de Erechim/RS. conheceu-se o status da Gestão Ambiental aplicada em 29 escolas públicas do município de Erechim, por meio de pesquisa de campo com entrevistas semiestruturadas aos membros responsáveis pela direção das escolas.

\section{METODOLOGIA}

O estudo foi realizado com os principais gestores das escolas que submetidos a entrevista, com o auxilio do questionário, colaboraram para o levantamento de dados referente à gestão ambiental. A entrevista consistiu em um roteiro que teve por objetivo obter informações dos atores sociais das escolas, objeto da pesquisa. O questionário continha 26 questões, com o intuito de orientar e facilitar a entrevista. Foram visitadas, no total, 29 escolas. Para manter o anonimato das escolas, foram criados códigos para identificá-las de $1 \mathrm{~A}$ a 2I. Foram feitas as seguintes observações gerais na pesquisa de campo:

Se escolas em estudo possuíam SGA e os requisitos que este deve possuir;

O que a direção entendia por GA e PGAE;

As medidas tomadas para minimizar os impactos ambientais;

De que maneira são trabalhadas as atividades de EA; GA e EA.

Qual a relação que a direção percebe entre

Ilustrou-se através de imagens fotográficas a realidade encontrada no dia a dia das escolas.

\section{RESULTADOS E DISCUSSÃO}

Conforme Maturano e Vieira (2010), a gestão ambiental visa o uso de práticas que garantam a conservação e preservação da biodiversidade, a reciclagem das matérias-primas e a redução do impacto ambiental das atividades humanas sobre os recursos naturais. A escola, nesse ínterim, como instituição social, seja ela de responsabilidade pública ou privada, tem como responsabilidade, no processo educativo, desenvolver ações que corrobore com o desenvolvimento sustentável. Sendo assim, não pode se eximir de aplicar um Programa de Gestão Ambiental, já que como qualquer outro empreendimento também causa impactos ambientais. Em outras palavras, a escola precisa vivenciar a sustentabilidade para ser propulsora da mesma.

Por meio de visitas e da aplicação do instrumento de pesquisa em 29 dessas escolas públicas do município de Erechim, foram coletados os dados analisados a seguir: 


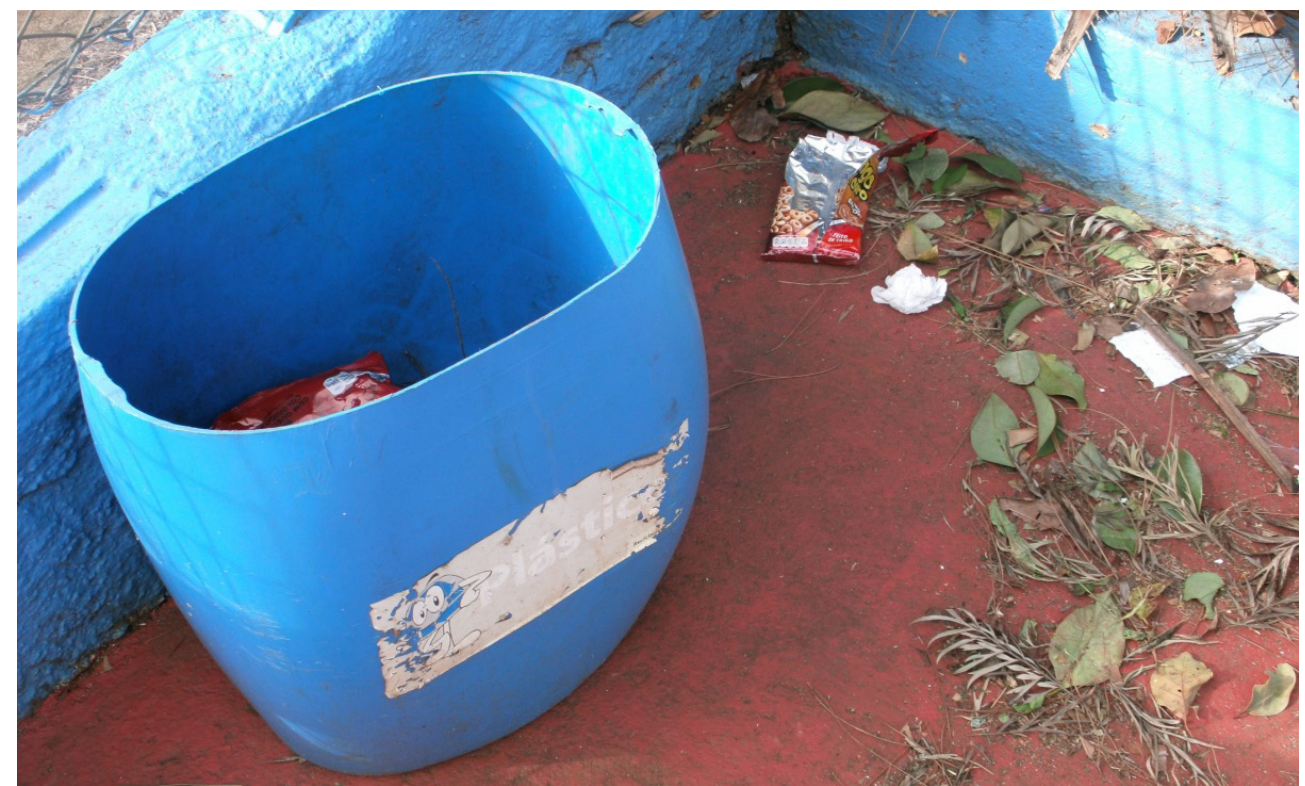

Figura 1 - Resíduos espalhados no chão na Escola.

Fonte: Autora, 2012.

1-Falta de cuidado com a disposição dos resíduos (figura 1). Além disso, a lixeira não estava identificada corretamente para a disposição dos plásticos, o que indica a necessidade de melhoria, visto que não seguia os padrões para identificação de lixeiras estabelecida pela resolução 275/01 do CONAMA (Brasil, 2012), onde a cor da lixeira deve ser vermelha, para a disposição de plásticos. Sugere-se, nesse caso, que a lixeira seja substituída por outra com cor adequada, conforme resolução citada anteriormente e reutilizada para o acondicionamento de papéis, onde a cor indicada de lixeira é azul. Além disso, há necessidade de se fazer um monitoramento contínuo para evitar que os resíduos fiquem dispostos no chão.

2-Resíduos da construção civil (resolução Conama 307/02). A escola não estava fazendo reformas e os resíduos encontravam-se aglomerados em um compartimento do pátio da escola, entre uma sala de aula e uma sala de informática (figura 2). Neste caso, percebeu-se que a direção ainda não tinha tomado nenhuma providencia para fazer o recolhimento dos resíduos.

3-Falta de cuidado com os canteiros da escola (figura 3), o que é um mau exemplo, visto que a escola deve dispor de ambientes que almejam

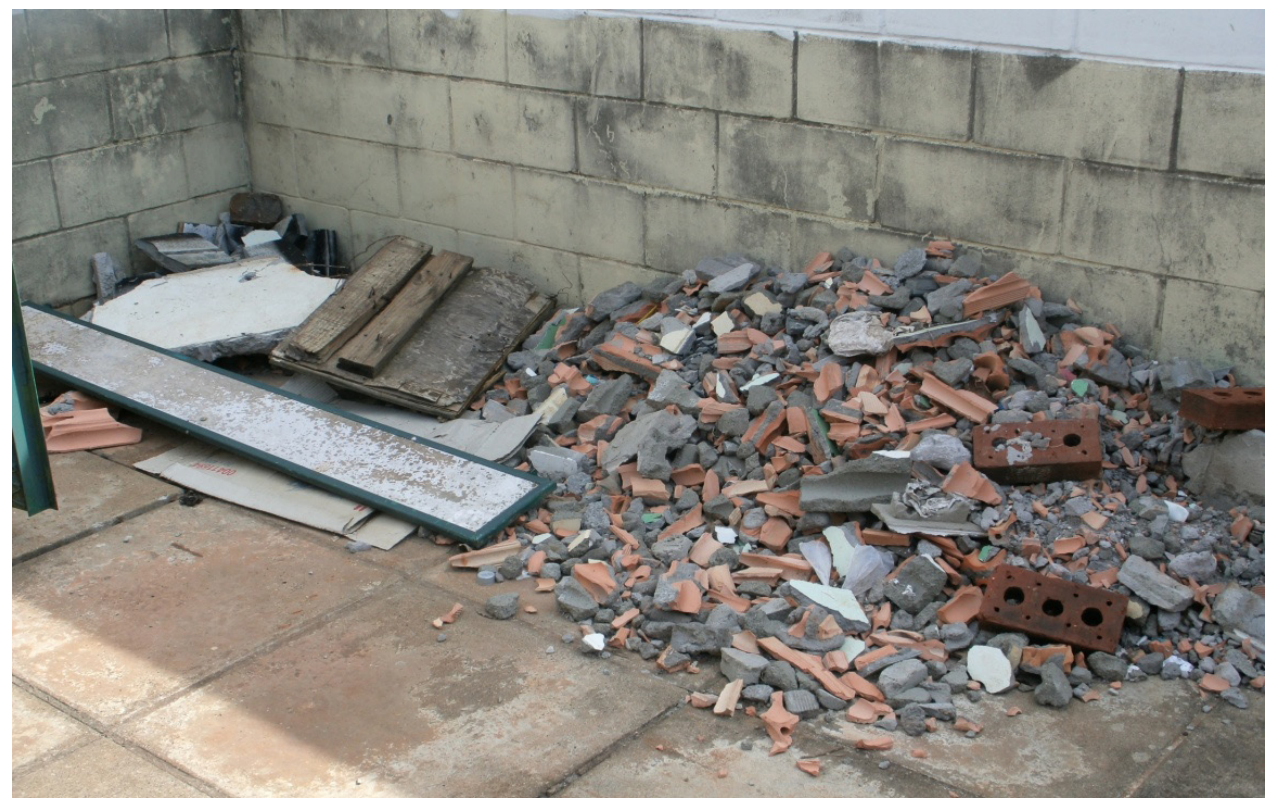

Figura 2 - Resíduos da construção civil na Escola.

Fonte: Autora, 2012 


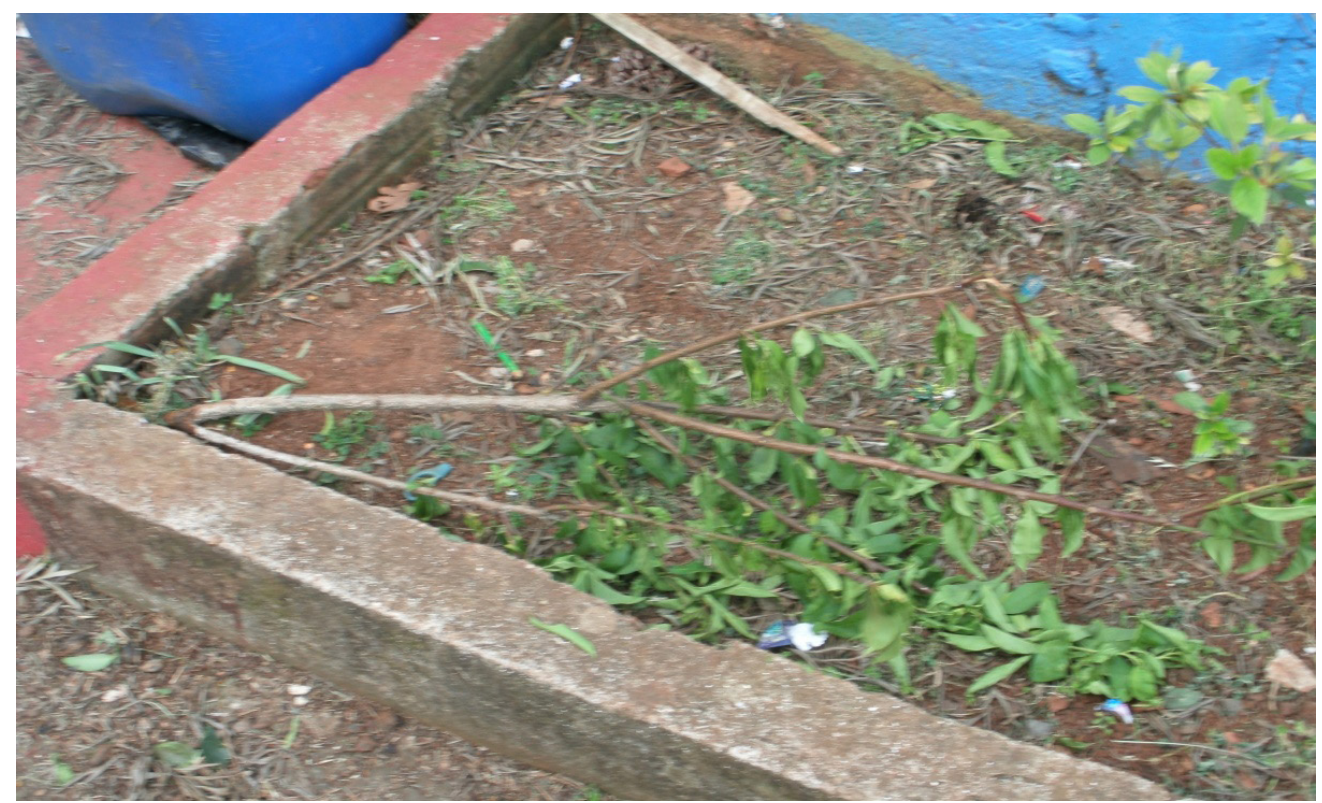

Figura 3 - Falta de cuidado com os canteiros na Escola.

Fonte: Autora, 2012.

o desenvolvimento sustentável, com canteiros bem cuidados que propiciam um bom aspecto visual. Sugere-se, então, um monitoramento mais efetivo para que os canteiros sejam bem cuidados, a grama esteja sempre bem aparada e que não haja resíduos nestes locais, tornando assim a escola mais atrativa visualmente, além de propiciar o cuidado com a flora característica deste local.

4-Poda irregular em uma árvore (figura 4), cujo corte foi feito sem o requerimento de licença, que deve ser emitida pelo órgão ambiental competente, neste caso a SMMA (Secretária Municipal de Meio Ambiente). A pedido da direção, a poda foi realizada por um funcionário, pois, segundo ela, parte do tronco atrapalhava no deslocamento dos alunos pelo pátio nos intervalos. Sugere-se que a instituição escolar, antes de fazer podas irregulares, encaminhe o pedido de licença para poda à SMMA, para evitar que a flora seja prejudicada. 5-As lixeiras para separação de resíduos perigosos encontravam-se irregulares (figura 5), pois a cores das lixeiras não estavam estabelecidas conforme dispõe na resolução 275/01 do CONAMA, que diz que os resíduos perigosos devem ser dispostos em lixeiras de cor laranja. A direção apenas soube informar que os resíduos são

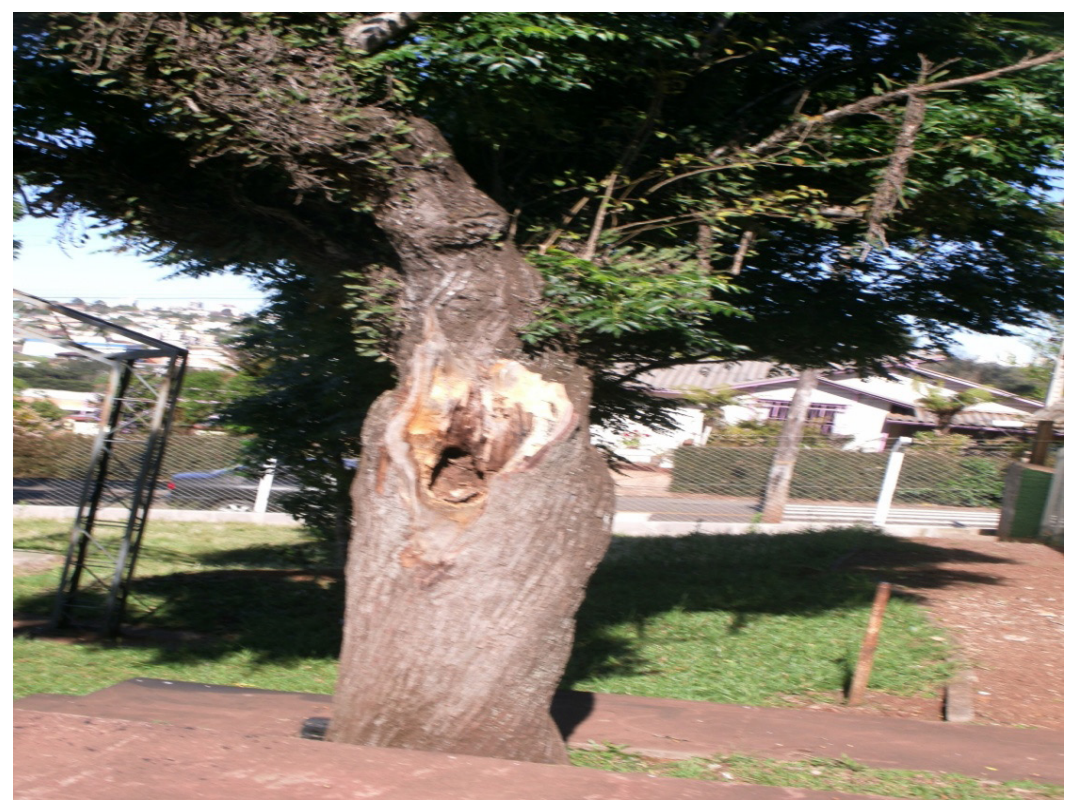

Figura 4 - Corte inadequado de uma árvore na Escola.

Fonte: Autora, 2012. 


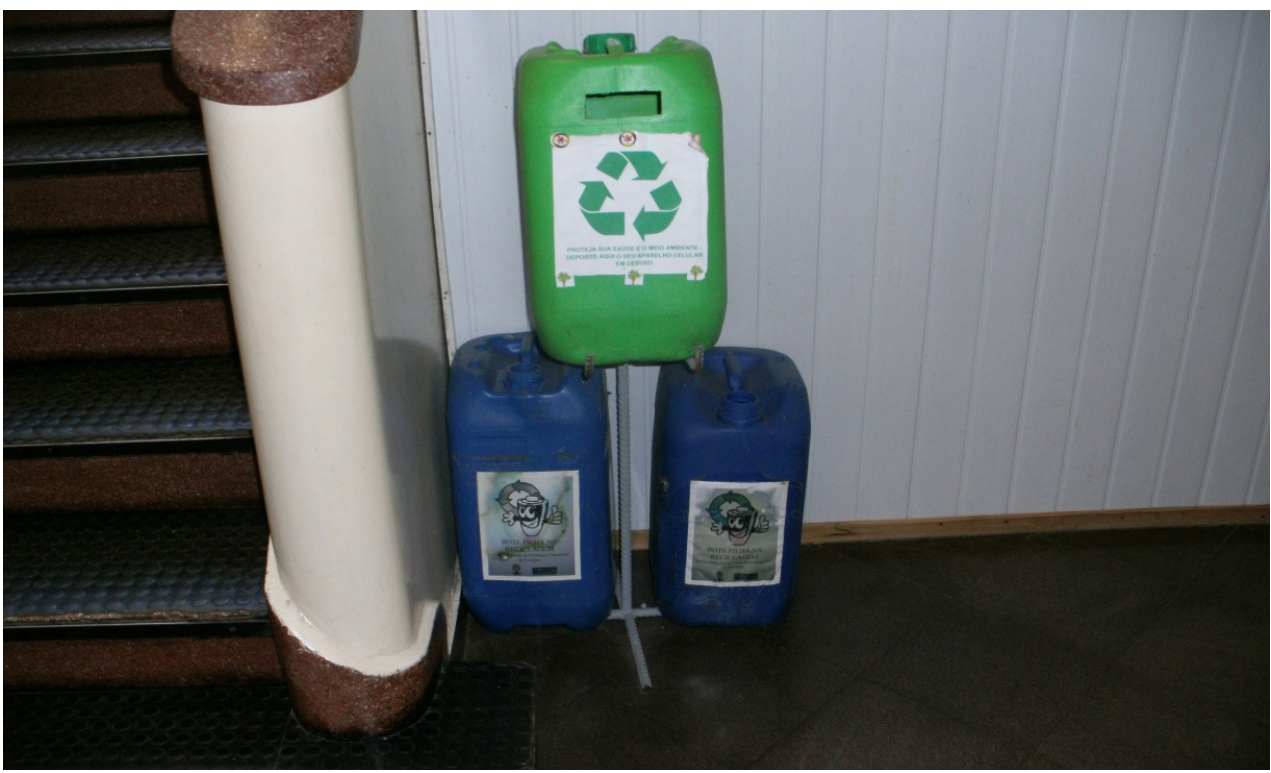

Figura 5 - Lixeiras para separação dos resíduos perigosos (pilhas, baterias e lâmpadas) na Escola. Fonte: Autora, 2012.

encaminhados à prefeitura municipal de Erechim e desconhece o destino que a mesma dá a estes resíduos.

6-A lixeira para o descarte dos resíduos secos era uma caixa de papelão feita pelos alunos (figura 6). A lixeira para o descarte dos resíduos orgânicos era identificada pela cor marrom, conforme estabelece a resolução 275/01 do CONAMA, porém haviam dispostos muitos resíduos que deveriam estar na lixeira dos resíduos secos (principalmente papéis).

A partir dessa observação, sugere-se que a administração da escola providencie uma lixeira de cor azul para o descarte dos papéis, conforme estabelece a resolução 275/01 do CONAMA.
Além disso, sugere-se também que seja feito o monitoramento contínuo, principalmente pelo professor (a) e, num segundo momento, pelos alunos, para que os dois tipos de resíduos tenham destino ambientalmente correto.

7-Na cozinha da Escola, embora as lixeiras estivessem tampadas e possuíssem pedal, não eram identificadas nas cores adequadas conforme resolução 275/01 do CONAMA, conforme mostra a figura 7. Sugere-se que, a lixeira para os resíduos orgânicos seja substituída por uma de cor marrom e, para os resíduos secos, deve-se ter uma lixeira azul para papéis, uma vermelha para os plásticos e uma verde para os vidros, de acordo com a mesma resolução.

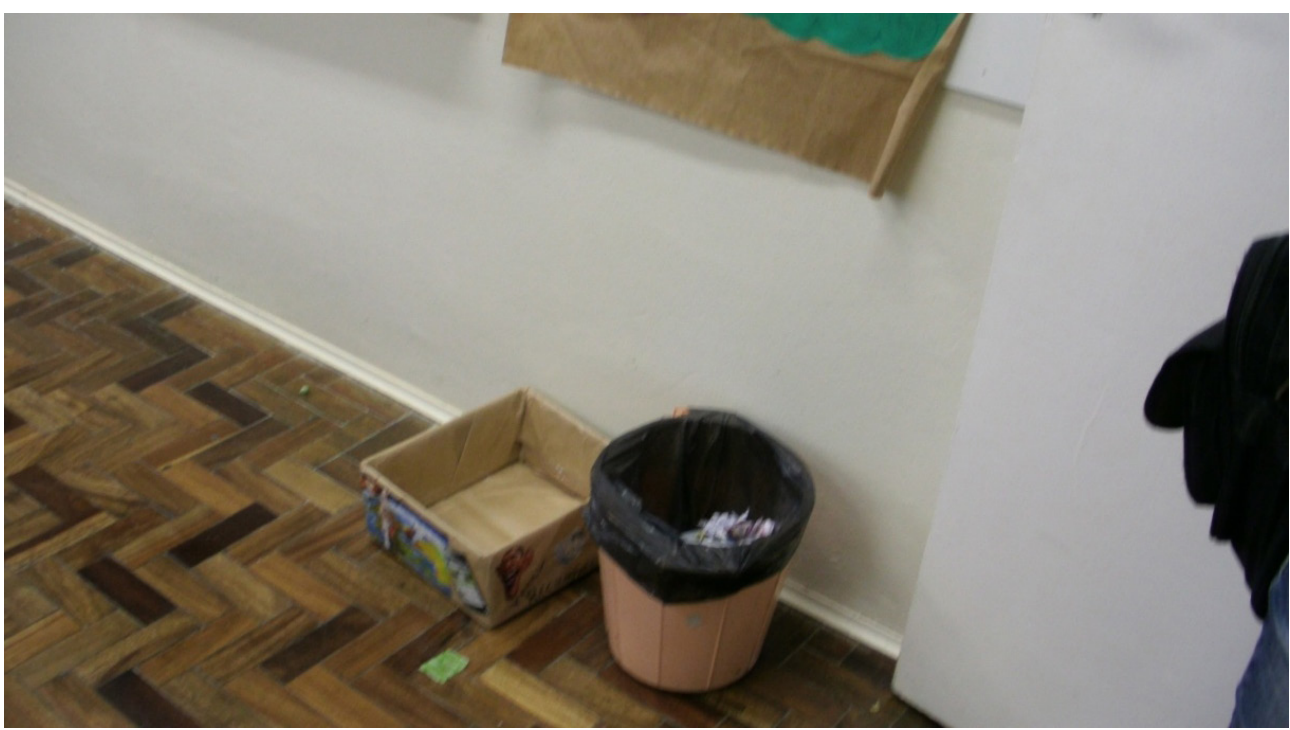

Figura 6 - Lixeiras para separação dos resíduos secos e orgânicos em uma sala de aula da Escola. Fonte: Autora, 2012. 


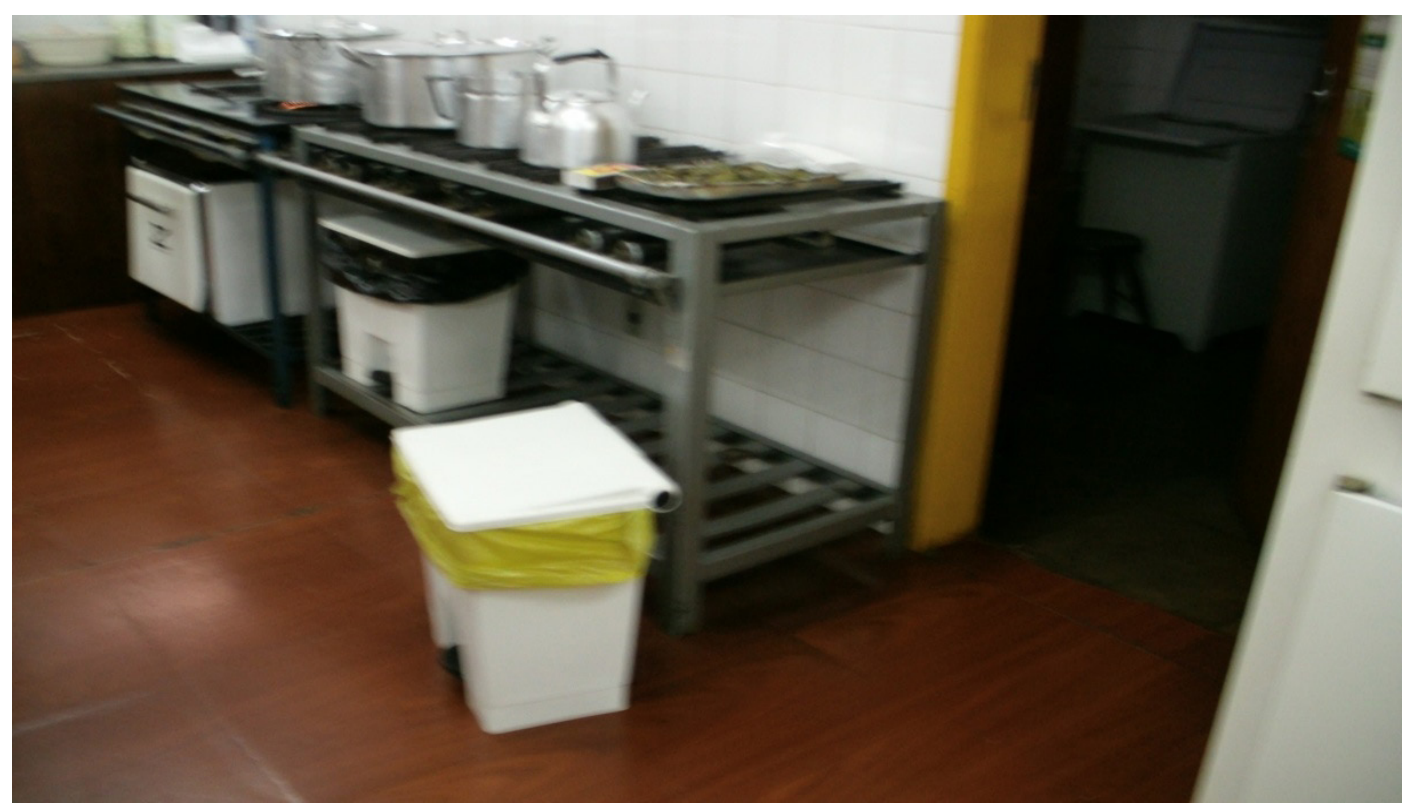

Figura 7 - Lixeiras para separação dos resíduos secos e orgânicos na cozinha da Escola.

Fonte: Autora, 2012.

Da mesma maneira que no caso anteriormente citado, fazer-se o monitoramento contínuo para que os resíduos sejam descartados nas lixeiras adequadas para cada tipo de resíduo. Este monitoramento pode ser feito, num primeiro momento, pelas cozinheiras, que podem ser responsáveis pela separação adequada dos resíduos neste departamento da escola, e, num segundo momento, pela administração.

Com base nas observações in loco a pesquisa avançou buscando investigar o que a direção da entendia sobre gestão ambiental. Nesse sentido, algumas das respostas foram:

Projeto permanente, que deve se incluir no projeto pedagógico. (Escola 3B)

Maneiras de evitar prejudicar o meio ambiente, questões como economizar água, conscientizar as crianças. (Escola 3F)

É o que fazer com o lixo, trabalhar com os alunos, atitudes. Trabalhamos com o uso consciente da água, dos recursos da escola. Gestão ambiental envolve todos os aspectos da escola, não somente recursos naturais. (Escola 1G)

Pensamos que o tema Gestão Ambiental, deve ser visto como conscientização, compromisso e responsabilidade, a partir de ações concretas e contínuas. (Escola 3D)

É um processo de sensibilização, da importância do meio ambiente. (Escola 2A)

É a contribuição para melhorar o meio ambiente. São projetos com meio ambiente. (Escola 3E)

É todo um trabalho que envolve planejamento, execução e monitoramento. São projetos na área ambiental. (Escola $2 \mathrm{H}$ )

É organizar, administrar, orientar. Por isso se precisa de um gestor ambiental. (Escola 1I)

Com base nessas respostas, percebeu-se que os entrevistados, de maneira geral, não têm muito bem definido o que é gestão ambiental. A maioria não entende que GA nada mais é que o gerenciamento dos aspectos ambientais, através de um SGA que vise a sustentabilidade ambiental. Sugere-se aqui novamente a importância de se implantar um PGAE nas escolas que venha a administrar todos estes aspectos.

A seguir questionou-se o que a direção da escola entendia sobre PGAE. Algumas das respostas foram:

Medidas adotadas para se ter Educação Ambiental. (Escola 3F)

Planos e projetos, fizemos o possivel e o impossivel para conscientizar, no sentido de cuidar de si próprio, do próximo e do meio ambiente. (Escola 1G)

Pensamos que o tema Gestão Ambiental, deve ser visto como conscientização, compromisso e responsabilidade, a partir de ações concretas e contínuas. (Escola 3D)

É um projeto contínuo sobre meio ambiente. (Escola 2A)

Fazer projetos em educação ambiental nas escolas. (Escola 1B)

Projetos pedagógicos e planos para se trabalhar com alunos. (Escola 1H)

Com base nessas respostas, constata-se que os entrevistados confundem PGAE com projetos de educação ambiental, os quais não envolvem 
os aspectos ambientais e nem mesmo todos os membros da escola, apenas os alunos.

Quando questionados em relação às medidas tomadas para minimizar os impactos ambientais a partir da identificação dos aspectos ambientais a direção posicionou-se assim:

Não são feitas, as funcionárias que realizam as atividades, mas encontramos problemas com elas na separação do lixo. (Escola 3B)

Procuramos controlar mais, mas a escola gera poucos resíduos. (Escola 1G)

Temos cuidado com as lixeiras internas e externas, palestras, professores de ciências trabalham em datas específicas sobre o meio ambiente para fazer a conscientização. (Escola 2A)

Fizemos educação ambiental, queremos instalar mais uma cisterna. (Escola 1B) (Escola 1C)

Separamos o lixo, fizemos reciclagem.

Separamos o lixo, cuidamos da grama, podas de árvores. (Escola 2E)

Procuramos separar certo o lixo. (Escola

Fizemos um melhor controle, mas não conseguimos atingir numa totalidade a melhoria. (Escola 1F)

Procuramos falar e educar mais, não só os alunos mas toda a escola.(Escola 3G)

Tentamos melhorar, por exemplo agora queremos colocar mais lixeiras. (Escola $3 \mathrm{H}$ )

Nota-se que os responsáveis pela direção das escolas não tem conhecimento sobre o que são aspectos ambientais e qual a importância da identificação destes para a obter-se a minimização dos impactos ambientais.

A figura 8 mostra uma cisterna instalada em 2009 na escola onde a água coletada da chuva é utilizada no processo de limpeza e irrigação dos jardins. Segundo a entrevistada, a vazão de água no telhado é muito boa, por isso a direção tem como meta instalar uma segunda cisterna.

Quanto às atividades de educação ambiental algumas das respostas foram:

Tem feira multidisciplinar de dois em dois anos e palestras com Secretaria Municipal de Meio Ambiente (SMMA). (Escola 3B)

Em forma de projetos, porém todo dia é enfatizado para preservar. (Escola 3F)

Em sala de aula, nos momentos de reflexões que é feito todos os dias, com palestras e projetos desenvolvidos durante o ano. (Escola $1 \mathrm{G}$ )

Filmes, textos reflexivos, teatro, pesquisas, visitas, etc. (Escola 3D)

Projetos coletivos, campanha sobre o lixo que é feita todos os anos, visitas ao Parque Longines Malinowiski, ao aterro sanitário e no bairro onde tem as nascentes do rio Tigre. (Escola 2G)

Os professores trabalham as questões ambientais, os seminários integrados sempre tem o tema meio ambiente. No projeto de limpeza, os alunos desenvolvem um produto feito com cinza e água e utilizam em sala de aula. (Escola $2 \mathrm{H}$ )

Fizemos projetos sobre os rios de Erechim, reciclagem e reaproveitamento de alimentos. (Escola 2C)

Fazem-se atividades em sala de aula, palestras. (Escola 1A)

Com base nessas respostas, infere-se que

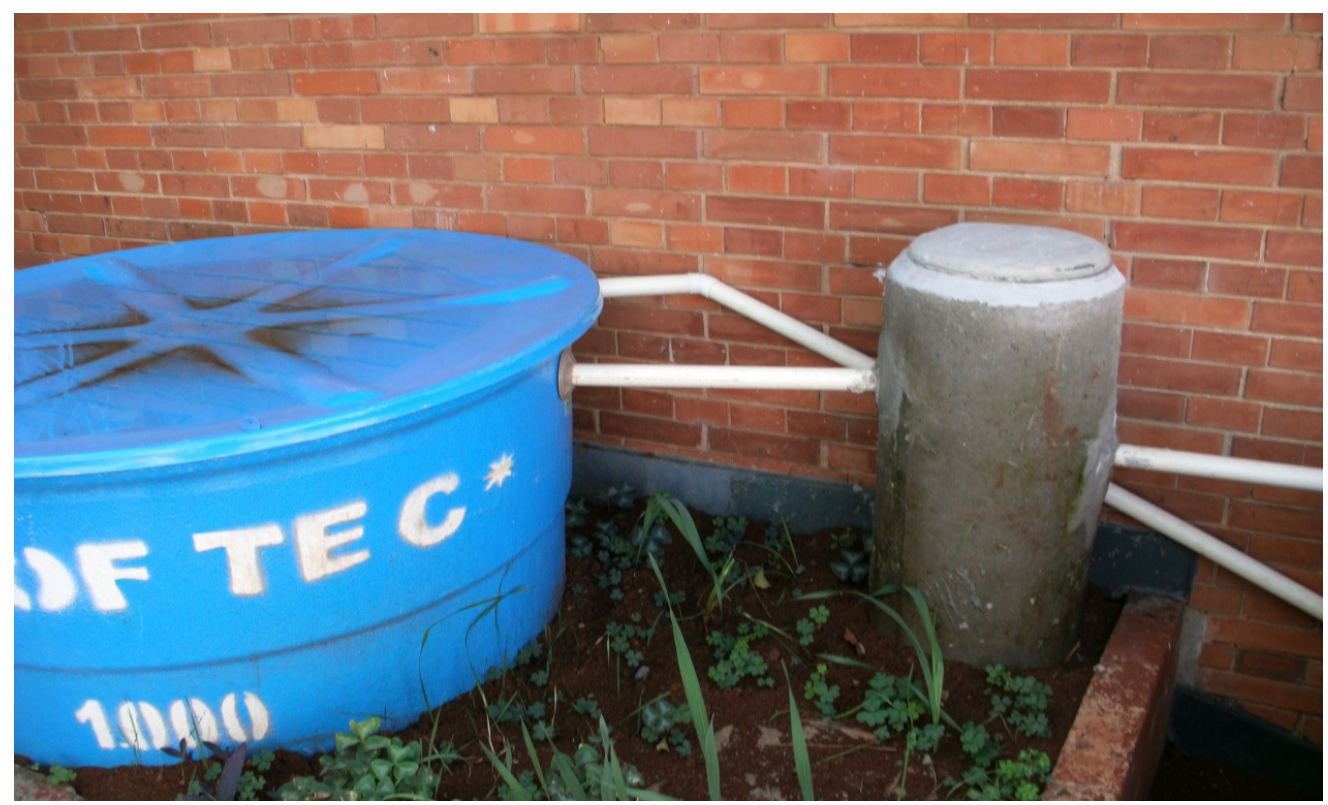

Figura 8 - Cisterna na Escola.

Fonte: Autora, 2012. 
a educação ambiental é bastante trabalhada nas escolas, e envolve todas as séries e todas as disciplinas, através de projetos anuais. Questiona-se, entretanto, o modo pedagógico de ensino, onde professores discutem em sala de aula as boas práticas ambientais, porém nem eles mesmos e nem os alunos vivenciam a sustentabilidade ambiental no ambiente escolar, criando entre ambas a imobilidade perante a solução dos diversos problemas ambientais, por tratarem apenas de problemas que fogem da realidade do cotidiano de cada um. Nesse caso, sugere-se que o processo de educação ambiental ultrapasse os limites de uma sala da aula e que a sustentabilidade na escola seja exemplo para a efetivação de uma sociedade sustentável, com sujeitos capazes de interferir e propor melhorias nos diversos ambientes em que se encontram. Também se sugere que a educação ambiental seja propulsora da gestão ambiental escolar, envolvendo todos os membros da escola, e, ainda que gestão ambiental e educação ambiental sejam aliadas em busca de uma escola com boas práticas sustentáveis. Nesse sentido, o decreto $n^{\circ} 7.083$, de 27 de janeiro de 2010, que dispões sobre o Programa Mais Educação, tem, em seu inciso V, como um de seus princípios para a educação integral:

O incentivo à criação de espaços educadores sustentáveis com a readequação dos prédios escolares, incluindo a acessibilidade, e à gestão, à formação de professores e à inserção das temáticas de sustentabilidade ambiental nos currículos e no desenvolvimento de materiais didáticos. (BRASIL, 2012).

A relação entre Gestão Ambiental e Educação Ambiental merece uma atenção maior por parte das direções das escolas.

A GA norteia a escola não é responsável pela GA. (Escola 2A)

GA é o gerenciamento, planejar, organizar, ter política e objetivos. EA é uma questão mais pedagógica, para se perceber a necessidade de cuidar do meio ambiente. (Escola 3C)

GA é uma questão mais abrangente. EA é aquilo que se faz no dia - a- dia. (Escola 2B) 33

Sim, acho necessário ter um gestor ambiental para ajudar no gerenciamento dos aspectos. (Escola 3A)

Sim, através da GA irá se educar os alunos e preservar o meio ambiente. (Escola $3 \mathrm{H}$ )

Sim com certeza, quando se tem educação se tem gestão ambiental. A educação é contínua, permanente. (Escola 2H)

Sim, porque se pode ter uma GA e nem todos estão educados para gerir a GA. Nem todos tem consciência. (Escola 1F)

GA é gerir tudo aquilo que nos cerca e EA é educar para que todos cuidem do meio ambiente, inclusive na escola. (Escola 1E)

GA é um trabalho que se realiza voltado ao gerenciamento da educação ambiental. (Escola 2D)

Sim, EA dá a conscientização para ocorrer a GA. (Escola 2G)

Uma complementa a outra, a educação se envolve na gestão. (Escola 1B)

Sim, conscientizar e orientar são um processo contínuo e isso se faz na gestão ambiental. (Escola 1H)

Com base nessas respostas, percebe-se que os entrevistados têm noções básicas da relação entre GA e EA, mas que ainda não são suficientes no sentido de compreender que a EA se insere no processo de GA. Há confusão entre os conceitos. Por isso, sugere-se que a EA não seja somente trabalhada em sala de aula, isoladamente, e sim esteja inserida no processo de gestão ambiental escolar, que pode ser posta em prática com a implementação de PGAE.

\section{CONCLUSÕES}

Notou-se, no decorrer desta pesquisa, que nenhuma das 29 escolas visitadas possui um SGA, inexiste a identificação dos diversos aspectos ambientais, dá-se foco principalmente a separação dos resíduos secos e orgânicos e não são tomadas medidas mitigadoras de impactos ambientais, uma vez que as direções das escolas não se sentem responsáveis pela gestão ambiental escolar.

O status da GA praticada nas escolas é inexistente, visto que os administradores desconhecem o que é gestão ambiental e qual a sua importância para o enfrentamento dos desafios socioambientais. Estabelecida a importância da relação entre GA e EA no levantamento teórico deste trabalho, notou-se que as escolas em estudo não estabelecem esta relação, que é fundamental para que se tenham boas práticas educativas $\mathrm{e}$ sustentáveis.

A proposta sugerida, portanto, é de que os administradores das escolas públicas sejam instrumentalizados por meio de um curso com conhecimentos específicos sobre GA e EA, conforme é previsto na PNEA (Política Nacional de Educação Ambiental) para que, posteriormente, possam aplicar esses conhecimentos nas instituições escolares que administram e, assim, auxiliá-los na implantação do PGAE. 
Sugere-se a implantação do PGAE, que tem o objetivo de suprir a falta de gerenciamento dos aspectos ambientais e mitigar possíveis impactos, visando melhorias contínuas. Desta forma, com a participação de todos os membros da escola vivenciando condutas, atitudes e ações vinculadas aos processos de GA e EA, acredita-se que é possível ter-se escolas sustentáveis para sociedades mais sustentáveis.

\section{REFERENCIAS}

BRASIL. Política Nacional de Educação Ambiental (Lei $\mathrm{n}^{\circ}$ 9.795, de 27 de abril de 1999). Brasília, DF: Senado Federal, 1999.

BRASIL. Agenda 21. Ministério do Meio Ambiente. Brasília, DF: 2012. Disponivel em: < http://www. mma.gov.br/responsabilidade-socioambiental/ agenda-21/agenda-21-brasileira> Acesso em 22 ago. 2012.

BRASIL. Resolução Conama No 275 de 25 de abril de 2001. Disponível em: <http:// www.mma..gov. $\mathrm{br} /$ por/conama/res/res01/res27501.html > . Acesso em: 08 out. 2012.

BRASIL. Resolução Conama $\mathrm{N}^{\circ} 307$ de 5 de julho de 2002. Disponível em: <http: // http:// www.mma.gov.br/port/conama/legiabre.cfm?codlegi $=307>$. Acesso em : 15 out.2012

BRASIL. Decreto $\mathbf{N}^{\circ} \mathbf{7 . 0 8 3}$ de 27 de Janeiro de 2010. (Dispõe sobre o programa Mais Educação). Brasília, DF: Senado Federal, 1999.

MARTURANO, Nadia Maria Pacheco; VIEIRA, Alex Sandro. Gestão Ambiental, Possibilidades para área degradada. Curso de Administração. Faculdade Cenecista de Capivari - CNEC, 2010.

VILELA JR, Alcir; DEMAJOROVIC, Jacques. Modelos e ferramentas de gestão ambiental: desafios e perspectivas para as organizações. São Paulo: Senac, 2006. 